\title{
Rates of smoking initiation among adolescents and young adults, 1907-81
}

\author{
David M Burns, Lora Lee, Jerry W Vaughn, Yu K Chiu, Donald R Shopland
}

\begin{abstract}
Objective-To estimate initiation rates among individuals aged 10-24 for the calendar years $1907-81$.

Design-Birth cohort analyses using a data set combining all of the National Health Interview Surveys asking questions about smoking.
\end{abstract}

Subjects - Multiple cross-sectional samples of the US population.

Results - Initiation of cigarette smoking was essentially a male behaviour at the start of the century, and a steep rise in incidence of smoking in white male adolescents occurred during the second decade of this century when mass marketing techniques were applied to cigarette sales and the US mobilised for World War I. A rapid rise in incidence of smoking in white female adolescents is noted in the late 1920s and 1930s, coinciding with the early efforts to target women with tobacco advertising. A dramatic increase in incidence of smoking for white male adolescents occurred during World War II. The incidence declined precipitously among white male adolescents, beginning in the late 1940s, and continuing through to 1980. In contrast, the incidence of smoking among white females remained constant through the 1950 s and early $1960 \mathrm{~s}$, and increased at the very end of the 1960 s and early 1970s. This increase in female incidence coincided with targeting of young women by advertising campaigns linking smoking with a slender female figure and the women's liberation movement. The increased incidence seen during the early 1970 s and in the 1955-59 birth cohort was limited to those female adolescents aged 17 years and younger.

Conclusion-The historical changes in the initiation of cigarette smoking presented in this paper, and their temporal association with gender-specific marketing and promotional activities, lend support to a link between cigarette advertising and promotional activities and initiation of cigarette smoking by adolescents and young adults.

(Tobacco Control 1995; 4 (suppl 1): S2-S8) Keywords: smoking initiation; adolescents; young adults
Introduction

Cigarette smoking, in contrast with other forms of tobacco use, is a behaviour largely limited to the 20th century. ${ }^{1}$ Per capita consumption of cigarettes in the US was 54 in 1900 and increased to a peak of 4345 in $1963 .^{2}$ Changes in per capita consumption were accompanied by changes in smoking prevalence, initially among males and subsequently among females. ${ }^{1,3,4}$

Changes in US per capita consumption of cigarettes since 1900 have been examined to assess the impact of factors promoting tobacco consumption, as well as tobacco control strategies. ${ }^{5,6}$ Changes in consumption data per capita can be produced by reductions in the number of cigarettes smoked per day by smokers, by individuals quitting for short periods of time and then relapsing, by reduced initiation of smoking, by long-term successful cessation or by a combination of these changes; and consumption data alone do not allow separation of tobacco use by gender or differentiate between initiation of tobacco use as cigarettes and switching from other forms of tobacco to cigarettes.

Advertising and promotional activity is felt by many to be a critical factor in the initiation of cigarette use in adolescence. ${ }^{7,8}$ Data linking initiation of cigarette smoking to cigarette advertising and promotional activities continues to accumulate. ${ }^{9-12}$ The greater recognition of the "Smooth Joe" Camel advertising campaign by children and young adolescents than by adults suggests that at least some tobacco advertising campaigns may be targeted at children. Despite this evidence, the tobacco industry contends that marketing activities only influence brand choice and do not influence initiation.

Age-specific initiation rates among young women increased coincident with advertising campaigns targeting women in the late 1960 s and early 1970 s. $^{1.13,14}$ It appears that this increase is confined to female adolescents between ages 12 and 17 and is greatest among those with less than a college education.

We estimated incidence of smoking rates at ages 10-24 for the calendar years 1907-80 using a data set combining all of the National Health Interview Surveys that asked questions about smoking. 


\section{Methods}

NATIONAL HEALTH INTERVIEW SURVEYS

The National Center for Health Statistics, Hyattsville, Maryland, through the National Health Interview Surveys, has collected health information since 1964 from a probability sample of the civilian, non-institutionalised population of the US. From 1965 on, there has been a section on tobacco use included in the survey. We have combined all those surveys which have questions about smoking behaviour into a single data set for the analyses presented below. Individual surveys represent cross-sectional samples of the US population at different times, have different sample sizes, and different sets of questions on smoking behaviour.

Smoking supplements to the National Health Interview Surveys were undertaken during the following 15 calendar years: 1965, $1966,1970,1974,1976,1977,1978,1979$, 1980, 1983, 1985, 1987, 1988, 1990, and 1991. The sampling methods for these surveys change every decade and details concerning the survey methodology are reported elsewhere. ${ }^{15-17}$

Surveys before 1974 included smoking information on all adult members of a household collected from a single adult from the same household. There were differences in the demographic characteristics of self- and proxy respondents, but an analysis of the 1970 data showed that the smoking prevalence of selfrespondents in 1970 was consistent with the prevalence obtained for the same demographic subgroup in the more representative selfrespondent survey of $1974 .{ }^{18}$ Accordingly, we limit our analysis to only the self-report data from the 1970 and earlier surveys.

For our analyses we have included only adults 20 years of age and older so that the age range of the sample would be uniform across all survey years. Sample sizes varied between 10000 and 90000 adults, and each survey included questions on smoking behaviour. Birth year, which was present for every respondent, was used to categorise each respondent into one of 17 five-year birth cohorts (1885-89, 1890-94, 1895-99, 1900-04,... 1965-69). The total number of observations available for analyses is 460254 .

\section{SMOKING INITIATION}

Six surveys (1970, 1978, 1979, 1980, 1987, and 1988) asked all ever-smokers the question: "How old were you when you began to smoke cigarettes fairly regularly?", and $94.7 \%$ of ever-smokers in those survey years gave an age of smoking initiation. Overall, data from 85628 ever-smokers were available for analysis of initiation. A separate analysis was conducted for each birth-cohort/race/gender subgroup, but incidence rates presented in this paper are limited to those of white males and females. The smaller number of observations available for blacks resulted in unstable rates, particularly for the earlier cohorts. Analyses of initiation were formulated as survival analyses in which the entire subgroup was considered to be present in the population at the time of birth, and the age given by someone for starting to smoke fairly regularly was taken as the age or time of an event (starting to smoke). Each person without an event was included at the age attained at the time of the interview. The result of this analysis is a curve, $I_{t}(a)$, which shows the percentage of the cohort remaining non-smokers by age. The survival analyses were performed using the LIFETEST procedure of the SAS statistical software package. ${ }^{19}$ Computed ever-smoking prevalence curves were adjusted for the underestimation of eversmoking prevalence that results from differences in age-specific mortality rates between smokers and non-smokers using an approach described elsewhere. ${ }^{1}$

A second set of survival analyses was performed to estimate the percentage of the cohort remaining non-smokers using calendar year rather than age as the measurement of time. Knowing a person's birth year and reported age of initiation, the calendar year for starting to smoke could be computed.

\section{INCIDENCE RATES}

Initiation rates refer to the percentage of the population that initiates smoking at a given age or in a given calendar year, and therefore, use the entire population (current, former and never-smokers) as the denominator when calculating the percentage. Incidence rates refer to the percentage of the population at risk who initiates smoking at a given age or in a given calendar year, and use only the never-smokers in the population when calculating the percentage. Using birth cohort-specific prevalence of ever-smoking data by calendar year, ${ }^{1}$ we constructed cohort-specific incidence rates of smoking initiation by birth cohort. For a given calendar year, we calculated the difference between ever-smoking prevalences for that year and the previous year and then divided the difference in prevalence by the percentage of never-smokers in the cohort as of the previous year. The incidence rate is the percentage of never-smokers who become new smokers for that calendar year. Negative numbers were treated as zeroes in the calculations.

Incidence rates by single year of age were combined over all birth cohorts born between 1885 and 1969. Conspicuous peaks in incidence rates are evident at ages $16,18,20,25$, $30,35,40$, and 45 , with the maximum occurring at age 18 . There is an obvious digit preference pattern for both sexes when incidence rates are reported by age, both for even ages before 20 and for multiples of 5 after age 20.

Incidence rates for white males and white females were age adjusted by weighting the rate for each five-year birth cohort according to the proportion of the population in the age group during each census between 1900 and 1990. For survey years in which no census was taken, the nearest decennial census year was used.

Age-adjusted incidence rates were generated 
using those cohorts in which the median age was between 10 and 24 during the calendar year of interest. The age range of $10-24$ was selected to allow a consistent age group to be examined across time, and because most smoking initiation occurs during that age range. Early birth cohorts of white females had substantial initiation at older ages, but these analyses are confined to individuals who initiated at younger ages. The oldest birth cohort for whom sufficient numbers of observations were available for analyses was the cohort born between 1885 and 1890, thereby limiting the start of data availability to 1907 .

Incidence rates were estimated for the three cohorts whose mean age was between 10-24 rather than for individuals of that age range. Every five calendar years the oldest cohort would be dropped from the average and a new younger cohort added. This leads to imprecision in the age definition of the estimates as some individuals were younger and older than the mean value for the cohort, and therefore, may have been outside the age range defined for the estimates. In addition, there is a fivecalendar year periodicity to the average age of the individuals used to form the estimates. This periodicity is introduced by the substitution of a new younger cohort for the oldest cohort in the average every five years, and is evident in the raw data points in figure 1 . To minimise the effect of sampling variability and the five-year periodicity, the data were smoothed over calendar year. The "loess" smoother, available in the statistical software package S-PLUS (Statistical Sciences, Inc., Seattle, Washington, USA), ${ }^{20}$ is a local regression model which was set to use a linear fit over 10 years of data at a time. Predicted values and pointwise standard errors were computed using the "predict" function in S-PLUS. Figure 1 shows the raw rates, smoothed rates, and the pointwise standard errors for white males and white females.

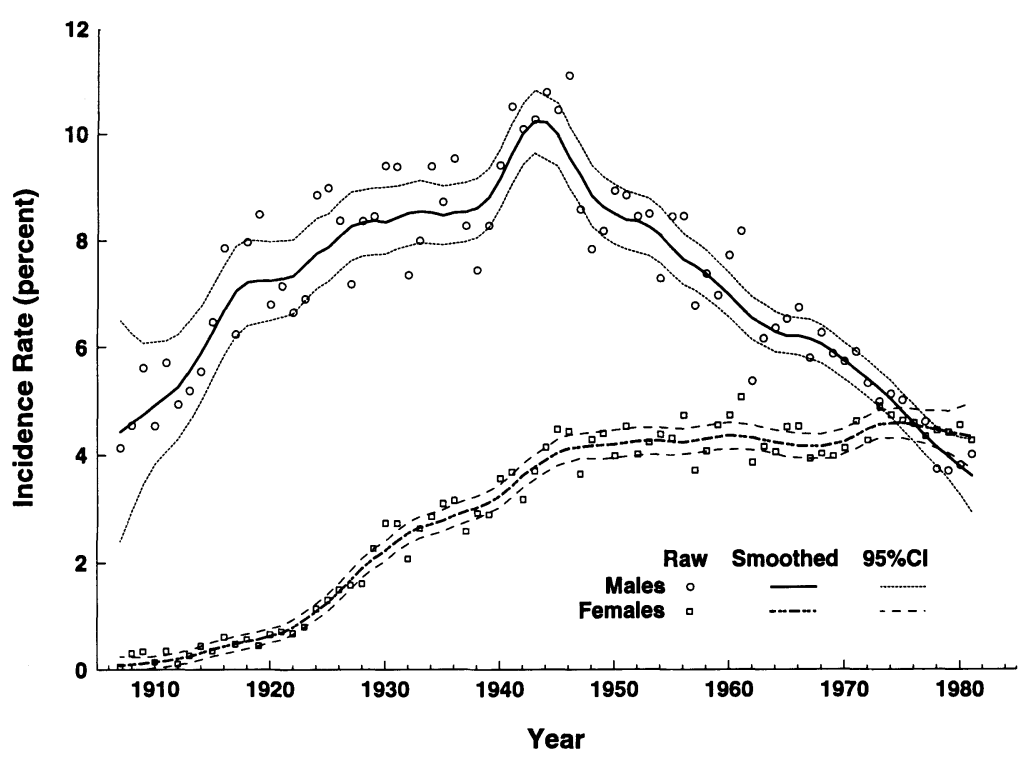

Figure 1 Incidence rates of smoking initiation in whites by calendar year, age adjusted by census year for birth cohorts with mean ages 10-24, birth cohorts 1885-1969.
COMPARABILITY OF THE DISTRIBUTION OF AGE OF INITIATION ACROSS SURVEY YEARS

We examined distribution of age of initiation for individual birth cohorts measured in different surveys conducted across a 20 calendaryear span and found no statistically significant differences in the distributions, allowing us to combine the distributions of age of initiation for individual birth cohorts across all of the surveys that contained initiation data.

\section{STATISTICAL INFERENCE}

We computed the exact binomial $95 \%$ confidence intervals for the prevalence and incidence rates estimated from the NHIS data. ${ }^{21}$ The rates were multiplied by the actual sample size (the number of individuals rather than the sum of the weights). The resultant pseudonumerator, together with the sample size, was used in computation of the confidence intervals.

To test for statistical significance in acceleration of incidence, the cohort samples were bootstrapped ${ }^{22}$ with the number of smokers randomly selected using a Poisson distribution with sampled number of smokers as the mean. The years of interest were split into two partitions and the difference between the initiation rates calculated. This was repeated 1000 times for each partition with the partition ranging from minimum year plus two to maximum year minus two. The distributions of these differences were verified to be normal, and finally the mean and standard error were calculated. A mean different from zero with no overlap in the standard error indicated a significant change in slope.

\section{Results}

Figure 1 shows smoking incidence rates for white males and white females over the period 1907-1981. The 95\% confidence intervals around the smoothed lines are also presented in the figure. Initiation of cigarette smoking was essentially a male behaviour at the start of the century, and there was a steep rise in male incidence rates from the start of data availability. There appears to be an acceleration in incidence beginning in 1913, but this change in rates did not achieve statistical significance. The most dramatic increases in male incidence rates occurred during the years 1915-20 and 1940-45. Incidence rates levelled off or declined after these periods of increasing incidence.

Incidence of smoking among women remained below $1 \%$ before 1924 and increased from $1.6 \%$ in 1928 to $2.3 \%$ in 1929 and $2.7 \%$ in 1930. The incidence of smoking increased during the period 1940-45, and the magnitude of the increase $(3.5-4.6 \%)$ in females was only slightly lower than that for males $(9.2-10.6 \%)$.

Initiation rates declined precipitously among white males beginning in the late $1940 \mathrm{~s}$, declining from $11.3 \%$ in 1946 to $3.8 \%$ in 1980. In contrast, initiation rates among white females remained relatively constant at $4.2 \%$ during the 1950s and 1960s, and increased 
slightly to $4.6 \%$ during the $1970 \mathrm{~s}$ ( $\mathrm{p}<0.02$ ). Beginning in 1976, incidence among female adolescents exceeded that among males.

CHANGES IN SMOKING INITIATION AMONG WOMEN IN THE LATE 1960S AND EARLY 1970s Differences in the incidence trends for white males and females during the early 1970s (downward in males and increasing among women) prompted a closer examination of initiation trends during this time period. Figure 2 presents the cumulative prevalence of ever-smoking at different ages among five-year birth cohorts of white women and white men for those birth cohorts born after 1940. A birth cohort comprised individuals born during specific calendar years, five-year groups in this presentation. Birth cohort analyses describe changes in smoking behaviour among individuals born during the same calendar years as they advance in age.
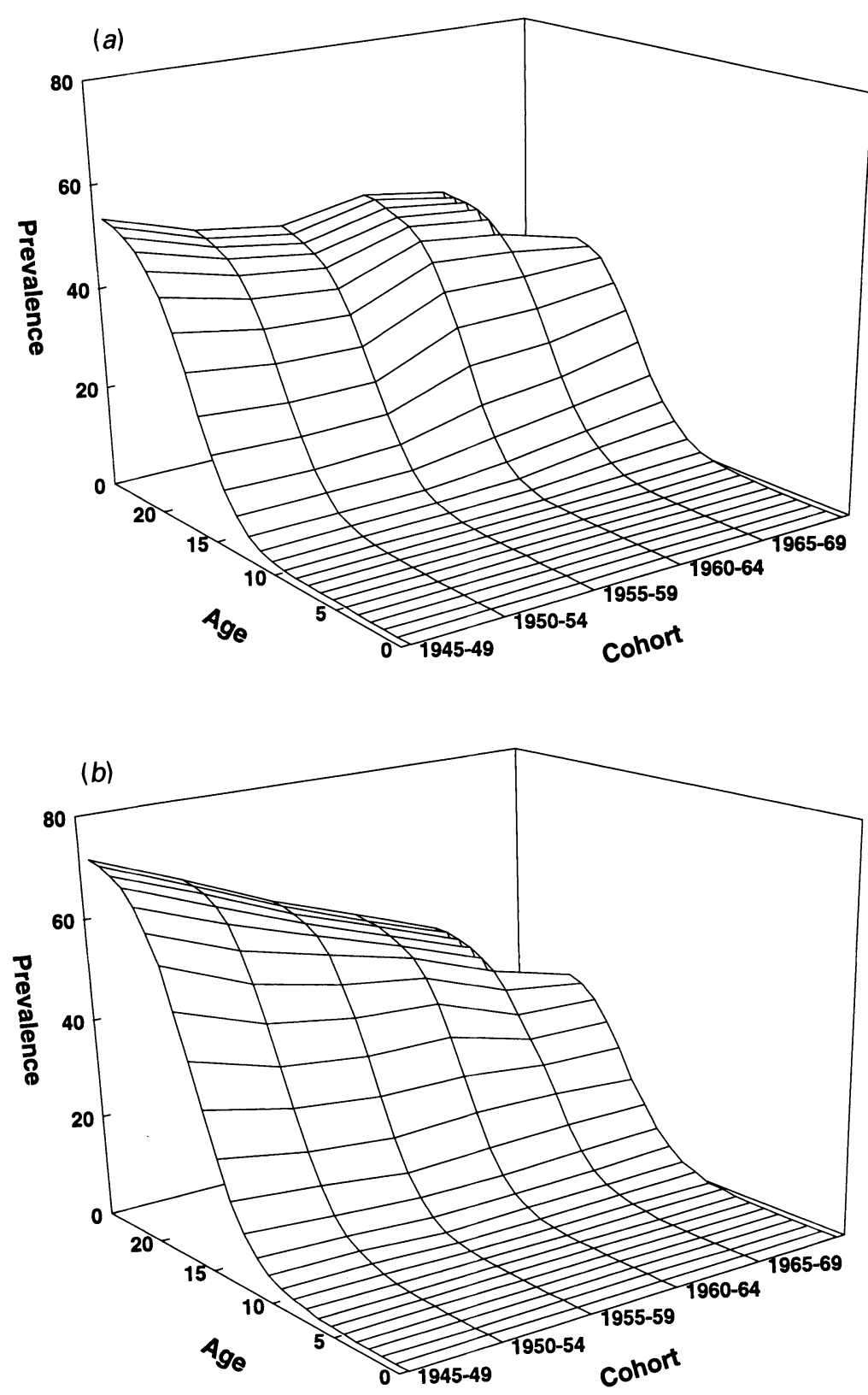

Figure 2 Ever-smoking prevalence of (a) white females and (b) white males by age for birth cohorts 1940-1969.
Each succeeding birth cohort of white females has a lower cumulative prevalence of ever-smoking at any age until the 1955-59 cohort. The prevalence of ever-smoking among members of this cohort of white females increases relative to the earlier cohort. Analyses of the same birth cohorts of white males show a continued decline in ever-smoking prevalence with each cohort, with no increase among the 1955-59 cohort. These data suggest that the increased incidence among white females noted in the early 1970s occurred beginning with the 1955-59 birth cohort (which was between 10-18 during the years 1970-74.

Figures 3 and 4 show the age distribution of smoking incidence for each of the cohorts of white males and females. At older ages, there is a systematic decline in incidence with each subsequent birth cohort among both males and females. Incidence rates before age 17 are relatively constant for the cohorts of white males born 1945-59, and a small decline in incidence rates at these younger ages is seen for later cohorts of white males. Incidence rates before age 17 among white females are lowest among those born 1945-54, are highest in the cohort born 1955-59 and decline in later cohorts. These data show that the increased ever-smoking prevalence among white females born 1955-59 was due entirely to increased incidence at younger ages, and that incidence rates at older ages actually declined among white females in the 1955-59 birth cohort compared with earlier cohorts.

Figures 5-8 show a comparison of agespecific incidence rates for each birth cohort of white males and females, and the $95 \%$ confidence intervals for the incidence rates. Incidence rates for the same age in each of the sequential cohorts connected as lines across the figure. There is one line for each single year of age. Incidence rates for single year of age are presented for each birth cohort of white males and white females born after 1945 . White males at the ages of 14 to 21 show decreasing incidence rates across the five birth cohorts (1945 to 1969), with a more marked decrease at ages 18 to 21 and no apparent trend for ages 12 and 13 (figures 5 and 6). In contrast, there is a significant increase in incidence rates among birth cohorts of white females age 17 and under when more recent cohorts are compared with those born before 1954 . Incidence rates at ages 13-17 are significantly higher in the 1955-59 cohort of white females than the same age incidence rates for the prior (1950-54) cohort (figure 7). The incidence rate for 12year-old white females is not significantly increased (in comparison with the 1950-54 cohort) until the 1960-64 cohort. A decreasing incidence across the cohorts is evident among those white females aged 18 to 21 , but decline is not as steep as that for males at the same ages (figure 8). Individuals born between 1955-59 were ages 13-17 during the calendar years 1968-76. Individuals born between 1960-64 were aged 12 during the calendar years 1972-76. 


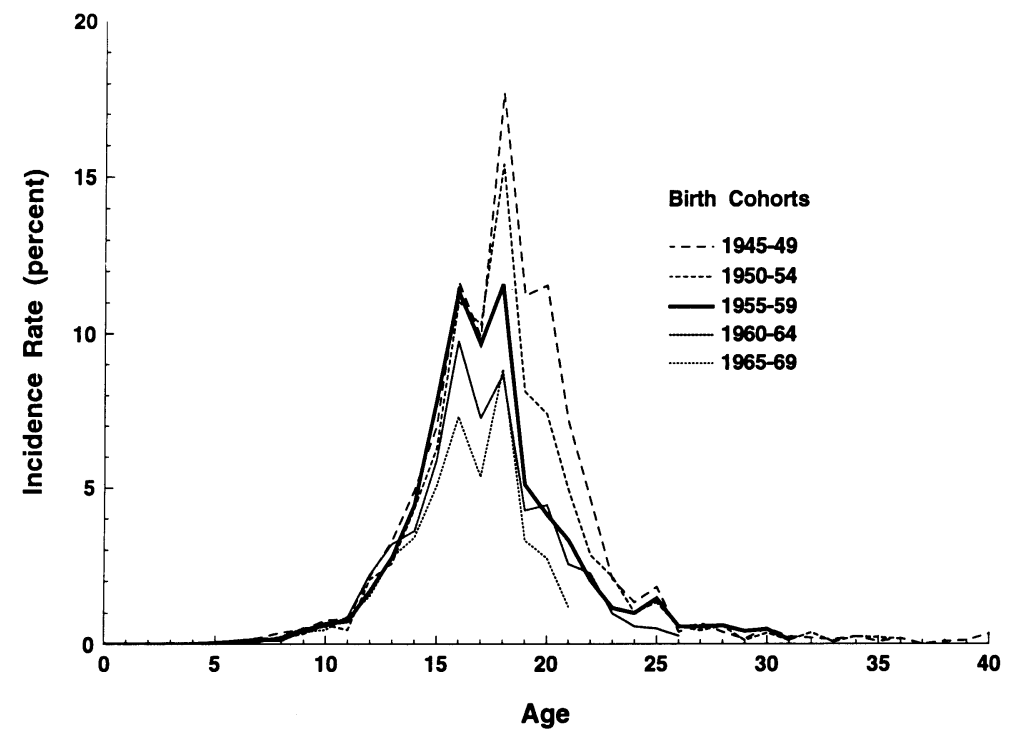

Figure 3 Incidence rates of smoking by age for white males, birth cohorts 1945-1969.

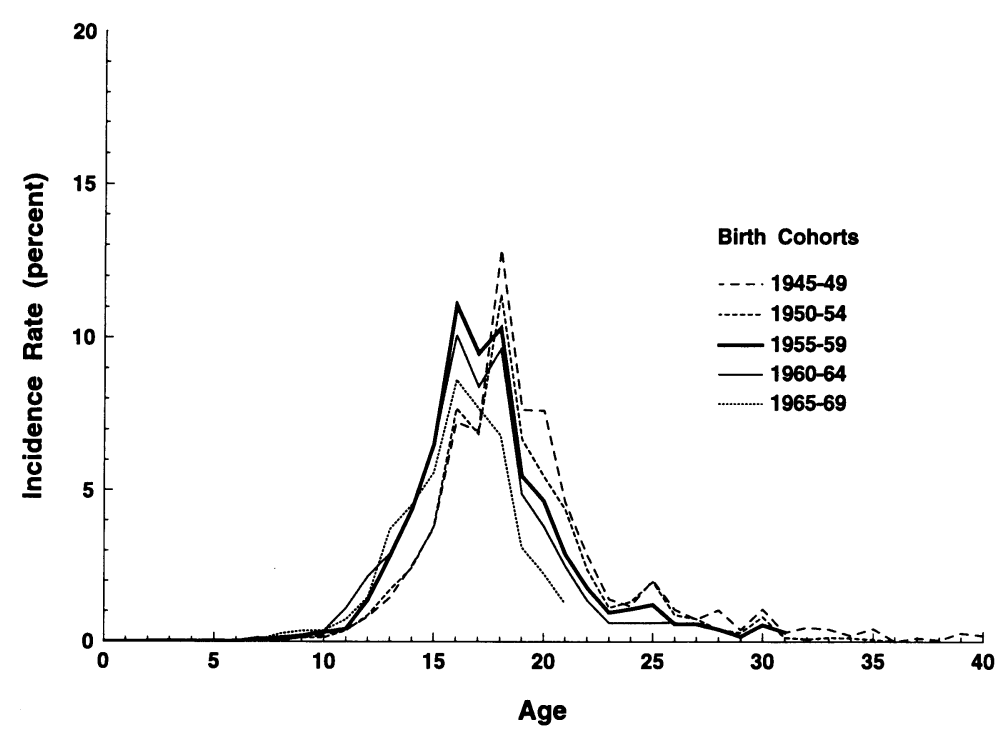

Figure 4 Incidence rates of smoking by age for white females, birth cohorts 1945-1969.

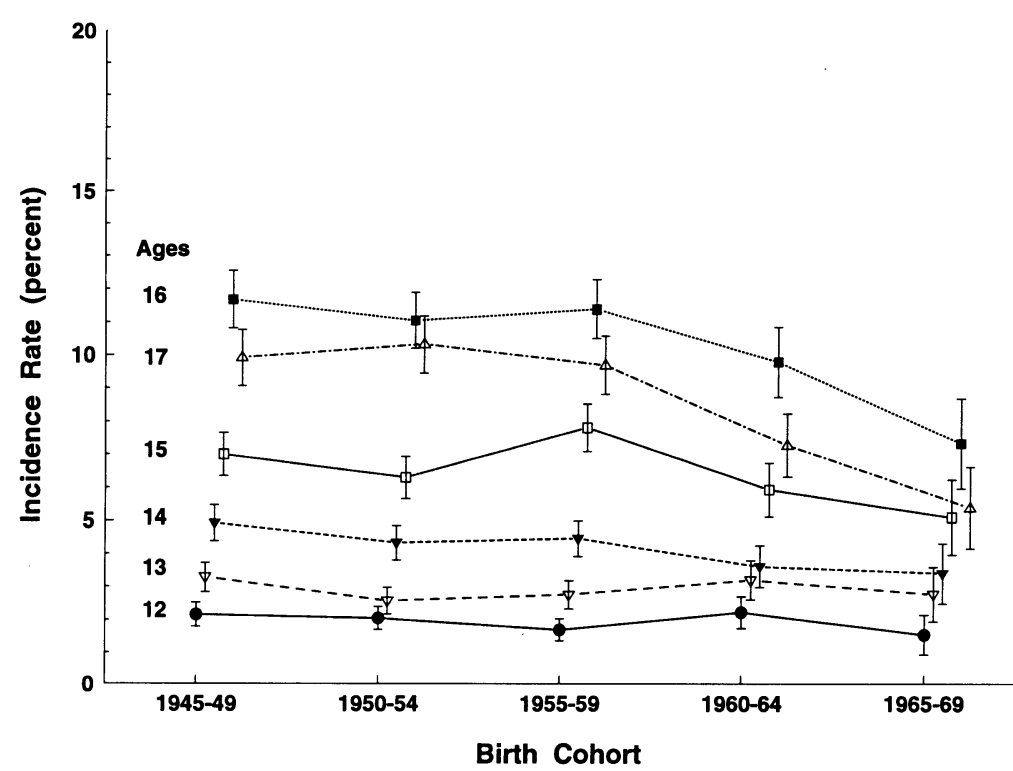

Figure 5 Age-specific incidence rates of smoking by birth cohort for white males, ages 12-17, birth cohorts 1945-1969.

\section{Discussion}

Cigarette manufacturers insist that advertising and promotional activities only influence brand preference among current smokers, and do not influence the initiation of cigarette smoking. Substantial changes in initiation of smoking by young individuals have occurred at different times during this century, however, and changes in incidence rates have not always been similar among white males and females. Increases in smoking incidence rates among young females have coincided with several large cigarette marketing and promotional efforts targeted at women.

Tobacco was commonly used in the American colonies and subsequently in the US during the 18th and 19th centuries but the predominant forms of tobacco used were chewing tobacco, snuff, pipes, and cigars. ${ }^{1}$ Widespread use of tobacco as cigarettes is more recent, occurring largely during the 20th century. Consumption of cigarettes per capita in the US was 54 in $1900,{ }^{2}$ in contrast with its peak of 4345 in 1993. Conversion of tobacco use from pipes, cigars, and chewing tobacco to cigarettes was enabled by the invention of machines that could mass produce cigarettes, eliminating the need for hand rolling, and by the development of safety matches, allowing a convenient, portable means of lighting cigarettes. ${ }^{23}$ However, the real growth in cigarette sales occurred following the application of advertising and mass marketing techniques to cigarettes during the second decade of this century. The remarkable growth in sales of Camel cigarettes following a national promotional campaign in 1913 established the power of advertising in promoting sales. ${ }^{24} \mathrm{It}$ set the stage for mass marketing of other brands of cigarettes and for a dramatic jump in cigarette use during the next several decades. ${ }^{24}$ Data presented in figure 1 show that the rise in cigarette sales and consumption per capita that resulted from the early mass marketing efforts was accompanied by a substantial rise in initiation of cigarette smoking among adolescent and young adult males and was not limited to conversion of users of other forms of tobacco to use of cigarettes.

Beginning in the late $1920 \mathrm{~s}$, advertising campaigns directed towards women began to appear. ${ }^{25}$ The most notorious of these campaigns were the "Blow some my way" and "Reach for a Lucky - instead of a sweet" series of advertisements. ${ }^{25,26}$ Incidence of smoking among young women, which remained flat at very low levels during the initial mass marketing campaigns, began to rise rapidly at the end of the 1920 s and continued to increase rapidly through the 1930 s.

It is worth noting that neither males nor females showed a fall in incidence rates during the period of the Great Depression in the US. In contrast, a $17 \%$ fall in consumption per capita occurred from 1929 to 1932 suggesting that the decline in consumption per capita during these years occurred because of a reduction in the number of cigarettes smoked per day or increased adult cessation rather than decreased initiation. 


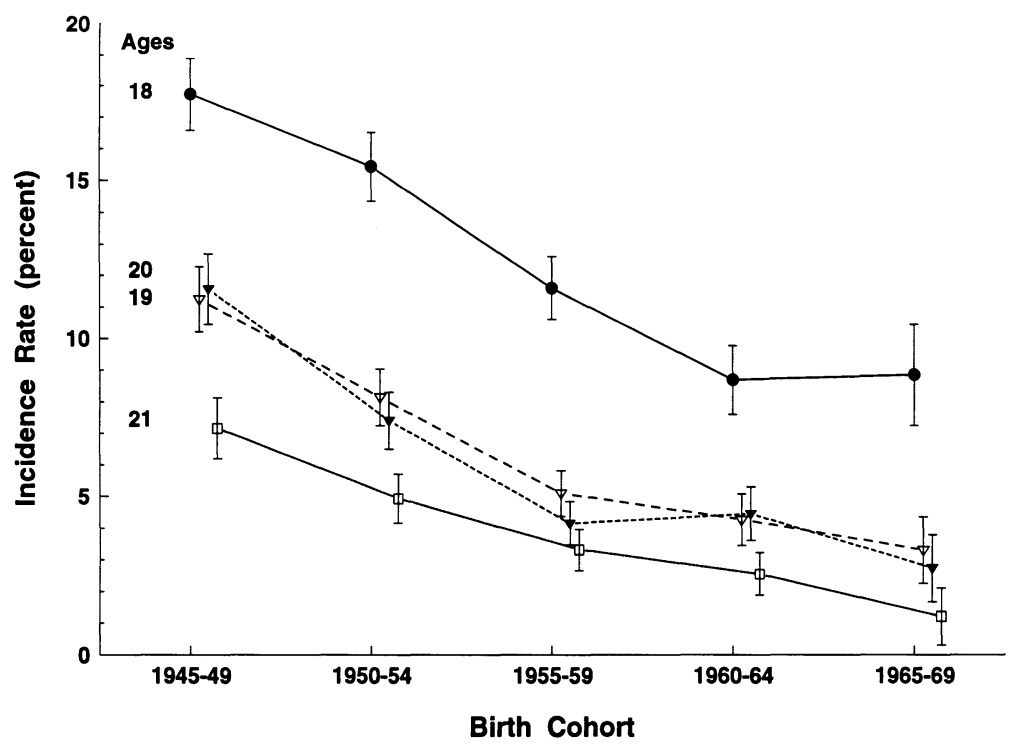

Figure 6 Age-specific incidence rates of smoking by birth cohort for white males, ages 18-21, birth cohorts 1945-1969.

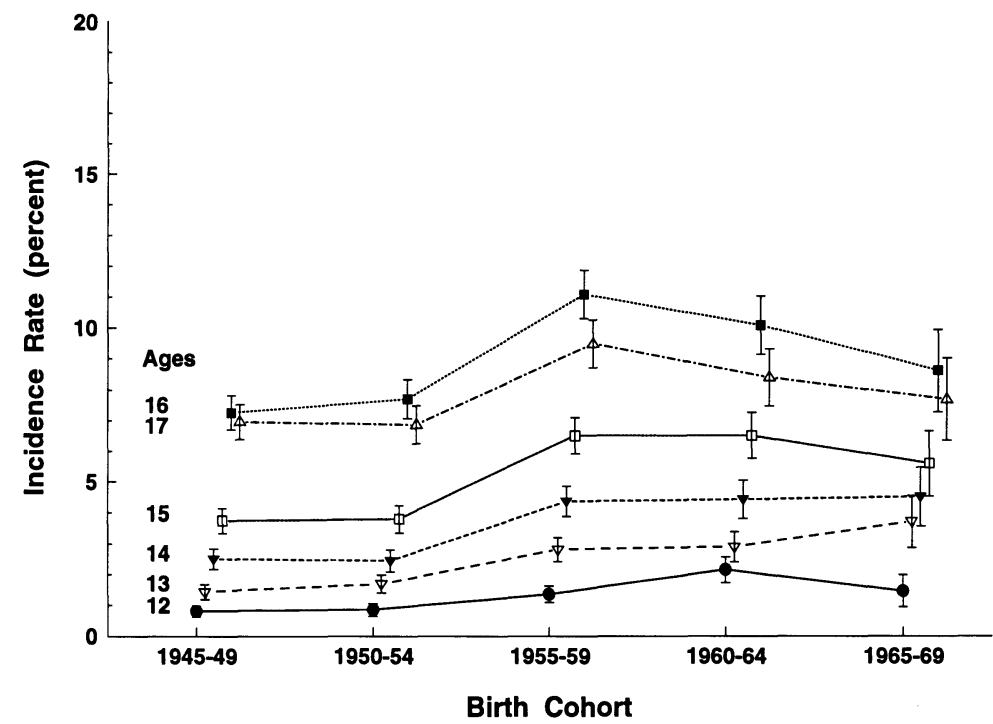

Figure 7 Age-specific incidence rates of smoking by birth cohort for white females, ages 12-17, birth cohorts 1945-1969.

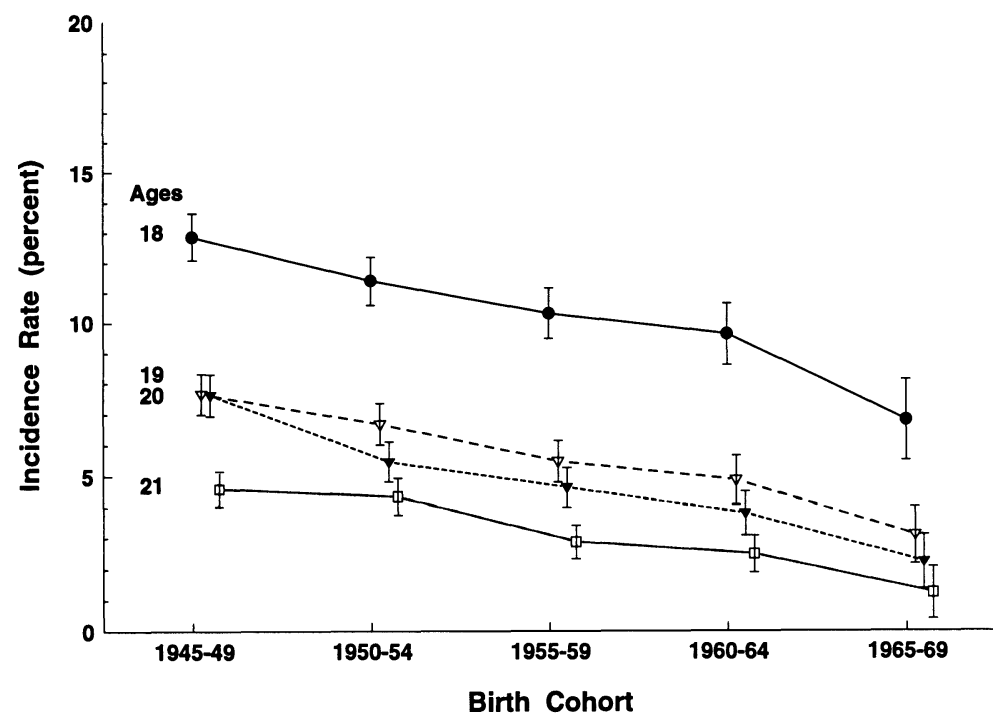

Figure 8 Age-specific incidence rates of smoking by birth cohort for white females, ages 18-21, birth cohorts 1945-1969.
Dramatic changes in consumption of cigarettes per capita occurred during each of the World Wars with the mobilisation of large numbers of men into the military during both wars and the recruitment of women into the workforce during the World War II. Cigarettes were included with the daily ration for soldiers in $1918^{23}$ and extensive marketing and free distribution of cigarettes to military personnel occurred during the World War II. ${ }^{23}$ These cigarette promotional activities are likely to have increased rates of initiation among men during the period of US mobilisation for both World Wars (1917-19 and 1941-45). White male incidence rates increased markedly during the US mobilisation for World War II, and declined just as markedly in the years immediately after the conclusion of the war and the resultant reduction in numbers of young males being inducted into the military.

Incidence rates among white males declined steadily from the mid-1950s to 1980 ; however, incidence rates among white females were constant from the mid-1940s to the mid-1960s. There is little suggestion that declines in consumption per capita observed with the release of the first Surgeon General's report in $1964^{27}$ or with the counter-advertising campaigns conducted from 1967-70, were accompanied by substantive changes in rates of initiation.

Conflicting directions in incidence trends for males and females are evident for the years beginning with the late 1960s. Incidence among young males decline, but rates among young women actually increase. Pierce et $a l^{13}$ linked this increase to the introduction in 1967 and marketing of brands of cigarettes targeted specifically at women using advertising themes of slenderness and linkage with the women's liberation movement. They used single year of age-specific incidence rates to show a rise in initiation among younger women during the 1968-73 period.

We have elected to examine the increased initiation among women during this period using a birth cohort approach rather than using age-specific rates over time. A birth cohort is comprised of individuals born during specific calendar years - five-year groups in this presentation. Birth cohort analyses describe changes in smoking behaviour among individuals born during the same calendar years as they advance in age. This format presents a more accurate picture of the life history of smoking than can be derived from examining the differences in smoking behaviour among different age groups in single, or multiple independent, cross-sectional samples of the population. Differences in smoking behaviours vary dramatically by year of birth in the US population, ${ }^{1,3,4}$ particularly for women, making interpretation of age-specific estimates from multiple cross-sectional samples over time difficult and often confusing. A given age group in cross-sectional surveys done at different points in time will contain individuals who were born in different years. In addition, the subdivision of the combined National Health Interview Survey data set into 
groups of people who are a single year of age at a single calendar year leads to small numbers of observations in many of the years of interest.

The birth cohort data presented confirm the conclusions drawn from the age-specific longitudinal analyses. ${ }^{13,14}$ The birth cohort (1955-59) that was in young adolescence during the introduction of women's cigarettes showed an increase in ever-smoking prevalence in comparison with the declining trend across sequential cohorts found among males and among females born from 1940 to 1954 . When distributions of age of initiation are compared for sequential cohorts, declines across birth cohorts in age-specific incidence rates occur among white males at all ages over 14, with the magnitude of the decline larger at older ages. Rates of initiation also decline across sequential cohorts of white women at ages 18 and over; but at ages 14-17 the birth cohorts born in 1955-59 and 1960-64 have higher rates of initiation than those preceding them.

These data, in conjunction with those of Pierce et $a l^{13}$, establish that there was an increase in initiation among white females coincident with the introduction and marketing of women's brands of cigarettes, and that this increase was largely confined to females under the age of 18 . This increase in incidence is present when the survey data are examined by age group across time $\mathrm{e}^{13,14}$ and when examined by age within birth cohort, as we have presented. The consistency of these two approaches makes it unlikely that the finding of an increased incidence of smoking among younger female adolescents during the late 1960 s and 1970 s is a result of confounding by age and cohort effects on the temporal trends.

Analyses of population-based trends, such as those presented in this paper, cannot establish a causal link between advertising and smoking initiation but can define a temporal association between introduction of new advertising and marketing approaches and increases in adolescent initiation. Temporal and quantitative relationships between timing of an advertising campaign, increase in brandspecific sales and the increase in initiation could provide more precise estimates of the temporal association of these phenomena and allow quantification of the strength of the association; quantitative data on advertising, however, are not currently available.

The historical changes in the initiation of cigarette smoking presented in this paper, and their temporal association with gender-specific marketing and promotional activities, lend support to a link between cigarette advertising and promotional activities and initiation of cigarette smoking by adolescents and young adults.

1 Burns D, Lee L, Shen Z, et al. Cigarette smoking behavior in the United States. In: Prospective mortality studies of smoking and disease. Smoking and Tobacco Control MonoHealth and Human Services, National Institutes of
Health, National Cancer Institute, 1995: chapter 2. In press.

2 US Department of Health and Human Services. Surveil lance for selected tobacco-use behaviors - United States, 1900-1994. Atlanta, Georgia: US Public Health Service, Centers for Disease Control, Office on Smoking and Health, 1994.

3 Harris J. Cigarette smoking among successive birth cohorts of men and women in the United States during 1900-80. f Natl Cancer Inst 71: 473-9, 1983.

4 Crane L, Herman-Shipley N, Tolley D. Smoking prevalences and lung cancer death rates. In: Burns D, Samet J, Gritz E, eds. Comprehensive approaches to tobacco J, Gritz E, eds. Comprehensive approaches to tobacco
control. Tobacco Control Monograph No 1. Bethesda, Maryland: US Department of Health and Human Services, Public Health Service, National Cancer Institute, 1992

5 Warner KE. The effect of the anti-smoking campaign on cigarette consumption. Am $\mathcal{F}$ Public Health 1977; 67 $645-50$.

6 Warner KE. Effects of the antismoking campaign: an update. Am f Public Health 1989; 79: 144-51.

7 Davis R, Current trends in cigarette advertising and marketing. N Engl f Med 1987; 316: 725-32.

8 US Department of Health and Human Services. Strategies to control tobacco use in the United States: a blueprint for public health action in the 1990 s. Bethesda, Maryland: US Public Health Service, National Institutes of Health National Cancer Institute, 1991: 3-31. (NIH Publication No 92-3316.)

9 US Department of Health and Human Services. Preventing tobacco use among young people. A report of the Surgeon General. Atlanta, Georgia: Public Health Service, Centers for Disease Control and Prevention, Office on Smoking and Health, 1994 (US Government Printing Office No S/N 017-001-00491-0.

10 Pierce JP, Gilpin E, Burns DM, et al. Does tobacco advertising target young people to start smoking? Evidence from California. $\mathscr{F} A M A$ 1991; 266: 3154-81.

11 DiFranza JR, Richards JW, Paulman PM et al. RJR Nabisco's cartoon camel promotes camel cigarettes to Nabisco's cartoon camel promotes cam
children. $7 A M A 1991 ; 266$ : 3149-53.

12 Fischer PM, Schwartz MP, Richards JW, Goldstein AO, Rojas TH. Brand logo recognition by children aged 3 to 6 years: Mickey Mouse and Old Joe the Camel. $\mathcal{F} A M A$ 1991; 266: 3145-3148

13 Pierce JP, Lee L, Gilpin EA. Smoking initiation by adolescent girls, 1944 through 1988 . An association with targeted advertising. $\mathcal{F} A M A$ 1994; 271 : 608-11.

14 Gilpin EA, Lee L, Evans N, Pierce JP. Smoking initiation rates in adults and minors: United States, 1944-1988. Am f Epidemiol 1994; 140: 535-43.

15 Fiore MF, Novotny TE, Pierce JP, Hatziandreu E, Patel K, Davis $R$. Trends in cigarette smoking in the United States: the changing influence of gender and race. $f A M A$ States: the changing

16 US Department of Health and Human Services. The National Health Interview Survey design, 1973-84, and procedures 1975-83. Hyattsville, Maryland: National Center for Health Statistics, Public Health Service, 1985. (DHHS Publication No (PHS) 85-1320.)

17 US Department of Health and Human Services. Design and estimation for the National Health Interview Survey, 1985-94. Hyattsville, MD: National Center for Health Statistics, Public Health Service, 1989. (DHHS Publication No (PHS) 89-1384.)

18 Gilpin EA, Pierce JP, Cavin SW, et al. Estimates of population smoking prevalence: self vs proxy reports of

19 SAS Technical Report P-179. Release 6.03. Cary, North Carolina: The SAS Institute, 1988; 49-90, and SAS/ Carolina: The SAS Institute, 1988; 49-90, and SAS/
STAT User's Guide. Release 6.03. Cary, NC: The SAS STAT User's Guide. Releas
Institute, 1988; 675-712.

20 Chambers IM, Hastie TJ, eds. Statistical models in $S$. South Pacific Grove, California: Wadsworth and Brooks/Cole Advanced Books and Software, 1992; 314

21 Larsen RJ, Marx ML, eds. An introduction to mathematical statistics and its applications. 2nd ed.Englewood Cliffs, New Jersey: Prentice-Hall, 1986.

22 Efron B and Tibshirari R. An introduction to the bootstrap. London: Chapman \& Hall, 1993.

23 Whelan EW. A smoking gun: how the tobacco industry gets away with murder. Philadelphia, Pennsylvania: George F Stickley.

24 Burrough B, Helyar J. Barbarians at the gate. New York, New York: Harper Perennial, 1990

25 Health Advocacy Center. Sixty years of deception: an analysis and compilation of cigarette ads in Time magazine, analysis and compilation of cigarette ads in Time magazine, 1925-1985. Vol 1: 1925-1939.

26 National Cancer Institute. Tobacco and the clinician interventions for medical and dental practice. Smoking and Tobacco Control Monograph No 6. Bethesda, Maryland US Department of Health and Human Services, Nationa Institutes of Health, National Cancer Institute, 1994 3-12.

27 US Public Health Service. Smoking and health: a report of the advisory committee to the Surgeon General of the Public Health Service. Atlanta, Georgia: US Department of Health, Education and Welfare, Public Health Service, Center for Disease Control, 1964. (Public Health Service Publication No 1103.) 